\title{
Consequences of atmospheric nitrogen deposition in terrestrial ecosystems: old questions, new perspectives
}

\author{
Hormoz BassiriRad
}

Received: 11 October 2014 / Accepted: 14 October 2014 / Published online: 19 November 2014

(C) Springer-Verlag Berlin Heidelberg 2014

The anthropogenic production of reactive nitrogen $(\mathrm{N})$ and the atmospheric fluxes of this growth-limiting resource onto native ecosystems have been the focus of thousands of papers over the past four decades. Records from the 1960s, 1970s and 1980s document unprecedented levels of N depositions, often exceeding tens of kilograms per hectare per year in Europe and North America. During the last decade or so, regulatory measures have led to the significant decline of the emission and deposition of reactive $\mathrm{N}$ (especially the oxidized forms) in eastern North America and Europe (Eshleman et al. 2013; Strock et al. 2014). While these declines may be interpreted as diminishing the importance of $\mathrm{N}$ deposition as a component of global change, there are compelling reasons to suggest just the opposite.

First, in regions of the world where $\mathrm{N}$ deposition rates have either stabilized or been reduced, they continue to be far above the background level. Despite the recent reduction in the emission rates of $\mathrm{N}$, eastern North America and Europe still remain as regions with some of the highest $\mathrm{N}$ deposition rates in the world (Vet et al. 2014; Zhang et al. 2012). For example, Zhang et al. (2012) estimated that over $35 \%$ of the contiguous US still receives more than $10 \mathrm{~kg} \mathrm{ha}^{-1}$ year $^{-1}$ of atmospheric $\mathrm{N}$ deposition. This is particularly revealing because we now know that deposition rates as low as $1-5 \mathrm{~kg} \mathrm{~N} \mathrm{ha}^{-1}$ year $^{-1}$ can have significant

Communicated by Russell Monson.

Dedication: to the memory of John Lussenhop (1941-2009) for his passion and contributions to soil ecology and an understanding of mycorrhizal fungi responses to $\mathrm{N}$ deposition

H. BassiriRad ( $\square)$

Department of Biological Sciences, University of Illinois at Chicago, 845 West Taylor Street, Chicago, IL 60607, USA e-mail: hormoz@uic.edu effects on ecosystem processes (Arens et al. 2008). It must also be noted that in regions where $\mathrm{N}$ deposition has stabilized or declined, the legacy effects of decades of $\mathrm{N}$ deposition are likely to override the declining rates of deposition, but little is known about such effects. Secondly, atmospheric $\mathrm{N}$ deposition in many regions of the world, including China and India (Vet et al. 2014; Liu et al. 2013), and most likely Brazil (Allen et al. 2011), is on the rise. These regions are home to some of the most productive and diverse ecosystems of the world whose responses to $\mathrm{N}$ deposition are still unknown. Third, even in regions where $\mathrm{N}$ deposition has been on the decline, the decrease is predominantly in the oxidized $\left(\mathrm{NO}_{3}{ }^{-}\right)$and not the reduced $\mathrm{N}$ form $\left(\mathrm{NH}_{4}{ }^{+}\right)$. Consequently, in many of these regions the ratio of the inorganic $\mathrm{N}$ forms is decisively shifting in favor of $\mathrm{NH}_{4}{ }^{+}$(Vet et al. 2014). It has been argued that the relative abundance of inorganic $\mathrm{N}$ forms may be a more important factor than the absolute amount that affects communitylevel processes (Lane and BassiriRad 2002; Boudsocq et al. 2012; Britto and Kronzucker 2013).

Much of the earlier research designed to better understand the consequences of $\mathrm{N}$ deposition on terrestrial ecosystems was shaped by the $\mathrm{N}$ saturation model first proposed by Aber et al. (1989). More specifically, this model proposed a broader set of biogeochemical mechanisms that triggered $\mathrm{N}$ saturation followed by a decrease in net primary productivity (NPP) and forest decline. This conceptual framework is based on a reasonable set of theoretical assumptions, and early research provided numerous empirical confirmation of it in some systems. However, two and a half decades of cumulating research point out that the $\mathrm{N}$ saturation model may not fully capture the end results and/ or the underlying mechanisms. In fact, Aber et al. (1998) were among the first to revisit the $\mathrm{N}$ saturation model and pose a number of challenges that needed to be met to 
improve its predictive ability. For example, they proposed that the onset of $\mathrm{N}$ saturation in some systems could be considerably delayed if the biological uptake capacity of the system is poorly understood or underestimated.

This special section includes six papers which highlight a subset of such challenges. The papers presented here cover a range of topics and ecosystem types from acidic grasslands in Europe, to boreal forests in Canada, to alpine grasslands in China, to temperate forests in the Midwest and Northeastern USA. The main theme and focus of these papers fall into two distinct areas:

1. How do biological uptake capacity, specific pools and fluxes of $\mathrm{N}$ respond to chronic $\mathrm{N}$ inputs? Now more than ever before, improved techniques make it possible for accurate identification and assessment of important pools and fluxes of $\mathrm{N}$. The relative importance of these particular pools and fluxes is likely to be site specific and this highlights why we are currently unable to propose a mechanism that universally predicts ecological consequences.

2. Do plant species differ significantly in their responses to chronic $\mathrm{N}$ addition and what are the potential consequences for biodiversity? In many ecosystems that are experiencing high $\mathrm{N}$ input, a shift in species composition, encroachment of invasive species and more broadly, biodiversity, may be more critical response variables than NPP.

The first three papers focus largely on biological uptake and/or transformation of deposited N. The study by Templer et al. focuses on two class I wilderness areas of the Northeastern United States. These high-elevation forest ecosystems may be particularly sensitive to atmospheric pollution, but the scale of $\mathrm{N}$ deposition in these ecosystems and their responses are poorly understood. Comparative analysis of stable isotope of $\mathrm{NO}_{3}{ }^{-}$in atmospheric deposition and streams led this team to conclude that atmospheric $\mathrm{N}$ is being biologically converted as it moves through the watersheds, rather than directly passing through. They also found that the cycling of N, particularly the rate of throughfall for $\mathrm{NH}_{4}^{+}$, is significantly different in conifer compared to deciduous forest sites. Finally, they concluded that these class I wilderness areas are not $\mathrm{N}$ saturated.

The rate of gaseous losses specifically through denitrification and how this responds to increased $\mathrm{N}$ deposition is the subject of the paper by Morse et al. The study was conducted at three hardwood forest sites in the Northeastern US representing a gradient of $\mathrm{N}$ deposition. They found that while denitrification in these forest sites is a significant proportion of the total $\mathrm{N}$ budget, the gaseous $\mathrm{N}$ losses through this pathway did not respond to increased
$\mathrm{N}$ deposition rates. This conclusion is particularly important for modeling efforts designed to assess the critical $\mathrm{N}$ load (see Pardo et al. 2011), and whether atmospheric $\mathrm{N}$ input can be markedly offset by denitrification. In the third paper featured here, Houle et al. examined long-term flux patterns for bulk precipitation, throughfall and canopy N uptake between 1997 and 2012 at two boreal forest sites in Quebec, Canada. The paper reports that overall, these boreal forest canopies retain more than $50 \%$ of the deposited $\mathrm{N}$. However, the rate of canopy inorganic $\mathrm{N}$ retention was generally higher for $\mathrm{NH}_{4}{ }^{+}$than for $\mathrm{NO}_{3}{ }^{-}$. More specifically, canopies retained an average of 65 and $50 \%$ of the deposited $\mathrm{NH}_{4}{ }^{+}$and $\mathrm{NO}_{3}{ }^{-}$, respectively.

The remaining three papers focus on community assemblages and whether individual species or functional groups respond differently to chronic $\mathrm{N}$ deposition. The study presented by Pannek et al. targeted a number of acidic grasslands in Northwestern Europe, including Germany and the Netherlands. They used both spatial and temporal gradient of $\mathrm{N}$ deposition along with other soil variables such as soil $\mathrm{pH}$ and $\mathrm{P}$ to assess the performance of 44 native species in these sites. $\mathrm{N}$ deposition was one of the most influential factors negatively affecting growth of 12 species, but positively affecting four others. The remaining target species did not significantly respond to deposition. The study has implications for conservation restoration of these acidic grasslands, but also provides strong evidence that $\mathrm{N}$ deposition can act as a strong selective force in shaping plant community dynamics.

Similarly, BassiriRad et al. found that the two dominant tree species, red oak and sugar maple, from Midwestern US temperate forest sites responded differently to $\mathrm{N}$ deposition. More specifically they reported that seedlings of oak, but not maple, responded negatively to 7 years of experimental $\mathrm{N}$ addition. They concluded that decades of $\mathrm{N}$ deposition is potentially a contributing factor to the observed historical trend of oak replacement by maple in these forest communities. Finally, $\mathrm{Li}$ et al. conducted a 4-year field experiment in an alpine grassland system in China and concluded that the effect of $\mathrm{N}$ deposition was conditioned by water availability. They found that increased $\mathrm{N}$ deposition rates generally improved the growth of grasses, but had a negative effect on forbs. Despite a clear difference between responses of grasses and forbs to increased $\mathrm{N}$ availability, there was no significant shift in species richness or other indexes of species composition.

Atmospheric $\mathrm{N}$ deposition will continue to be a major component of global change with potentially serious consequences for unmanaged ecosystems and plant communities. We hope the collection of papers assembled here sparks new ideas and approaches that would better inform experimental and modeling efforts yet to come. 


\section{References}

Aber JD, Nadelhoffer KJ, Steudler P, Melillo JM (1989) Nitrogen saturation in northern forest ecosystems. Bioscience 39(6):378-386

Aber JD, McDowell W, Nadelhoffer K, Magill A, Berntson G, Kamakea M, McNulty S, Currie W, Rustad L, Fernandez I (1998) Nitrogen saturation in temperate forest ecosystems-hypotheses revisited. Bioscience 48(11):921-934

Allen AG, Machado CMD, Cardoso AA (2011) Measurements and modeling of reactive nitrogen deposition in southeast Brazil. Environ Poll 159:1190-1197

Arens SJT, Sullivan PF, Welker JM (2008) Nonlinear responses to nitrogen and strong interactions with nitrogen and phosphorus additions drastically alter the structure and function of a high arctic ecosystem. J Geophys Res-Biogeosci 113:G03509

Boudsocq S, Niboyet A, Lata JC, Raynaud X, Loeuille N, Mathieu J, Blouin M, Abbadie L, Barot S (2012) Plant preference for ammonium versus nitrate: a neglected determinant of ecosystem functioning? Am Nat 180:60-69

Britto DT, Kronzucker HJ (2013) Ecological significance and complexity of N-source preference in plants. Ann Bot 112:957-963

Eshleman KN, Sabo RD, Kline KM (2013) Surface water quality is improving due to declining atmospheric $\mathrm{N}$ deposition. Environ Sci Technol 47:12193-12200

Lane DR, BassiriRad H (2002) Differential responses of tallgrass prairie species to nitrogen loading and varying ratios of $\mathrm{NO}_{3}{ }^{-}$to $\mathrm{NH}_{4}{ }^{+}$ratio. Funct Plant Biol 29:1227-1235
Liu X, Zhang Y, Han W, Tang A, Shen J, Cui Z, Zhang F (2013) Enhanced nitrogen deposition over China. Nature 494(7438):459-462. doi:10.1038/nature11917

Pardo LH, Fenn ME, Goodale CL, Geiser LH, Driscoll CT, Allen EB, Baron JS, Bobbink R, Bowman WD, Emmett B, Clark CM, Gilliam FS, Greaver TL, Hall SJ, Lilleskov EA, Liu L, Lynch JA, Nadelhoffer KJ, Perakis SS, Robin-Abbott MJ, Stoddard JL, Weathers KC, Dennis RL (2011) Effects of nitrogen deposition and empirical nitrogen critical loads for ecoregions of the United States. Ecol Appl 21:3049-3082

Strock KE, Nelson SJ, Kahl S et al (2014) Decadal trends reveal recent acceleration in the rate of recovery from acidification in the Northeastern U.S. Environ Sci Technol 48(9):4681-4689

Vet R, Artz RS, Carou S, Shaw M, Ro CU, Aas W, Reid NW (2014) A global assessment of precipitation chemistry and deposition of sulfur, nitrogen, sea salt, base cations, organic acids, acidity and $\mathrm{pH}$, and phosphorus. Atmos Environ 93:3-100. doi:10.1016/j.atmosenv.2013.11.013

Zhang L, Jacob DJ, Knipping EM, Kumar N, Munger JW, Carouge CC, Chen D (2012) Nitrogen deposition to the United States: distribution, sources, and processes. Atmos Chem Phys 12(10):4539-4554. doi:10.5194/acp-12-4539-2012 